\title{
OPEN Effect and mechanism of vitamin D activation disorder on liver fibrosis in biliary atresia
}

\author{
Song Sun ${ }^{1,4}$, Menghua Xu ${ }^{2,4}$, Peijun Zhuang ${ }^{3,4}$, Gong Chen ${ }^{1}$, Kuiran Dong ${ }^{1}$, Rui Dong ${ }^{1 凶}$ \& \\ Shan Zheng ${ }^{1 凶}$
}

To investigate the mechanism of 25 hydroxyvitamin $\mathrm{D}(25(\mathrm{OH}) \mathrm{D})$ deficiency in children with biliary atresia (BA) and its effect on liver fibrosis. The serum vitamin $D$ and $25(\mathrm{OH}) \mathrm{D}$, and expression of 25 hydroxylase (CYP2R1 and CYP27A1) in the liver of BA patients were detected and compared with those in the control group. We investigated the effect of differential expression of CYP2R1 in hepatocytes on the expression of genes related to liver fibrosis in primary hepatic stellate cells (HSCs) of BA and animal models of cholestasis. The ratio of $25(\mathrm{OH}) \mathrm{D} / \mathrm{vitamin} \mathrm{D}$ in the BA group was significantly lower than that in the control group. The mRNA and protein expression of CYP2R1 and CYP27A1 in liver tissue of the BA group was significantly lower than that in the control group. Exogenous active vitamin $D$ (calcitriol) inhibited the proliferation and migration of primary HSCs isolated from BA patients, and reduced the expression of fibrosis-related genes in vitro.

Downregulation of expression of CYP2R1 in hepatocytes increased expression of transforming growth factor (TGF)- $\beta 1$, collagen (Col)-1 $\alpha 1$ and tissue inhibitor of metalloproteinase (TIMP)-1, and decreased the expression of matrix metalloproteinase (MMP)-2 in cocultured primary HSCs of BA. Upregulation of expression of CYP2R1 in mice with bile duct ligation significantly increased the level of 25(OH)D, decreased the expression of TGF- $\beta 1, \mathrm{Col}-1 \alpha 1$ and TIMP-1, and increased the expression of MMP-2. Children with BA have impaired vitamin D activation due to CYP2R1 deficiency. The dysactivation of vitamin D can promote the proliferation and activation of HSCs and participate in the development of hepatic fibrosis in BA.

Biliary atresia (BA) is the most common biliary obstructive disease and the most common cause of jaundice in infants ${ }^{1,2}$. Hepatic portoenterostomy (HPE) before 90 days of age is the standard treatment for BA. Bile drainage was successfully established in $60-80 \%$ of the children with BA treated by $\mathrm{HPE}^{1}$; jaundice gradually decreased within 6 months, and liver function gradually tended towards normal. However, the majority of these children still had progressive liver fibrosis, which eventually progresses to cirrhosis, gastrointestinal bleeding and liver failure within a few years ${ }^{3}$. Therefore, exploration of the molecular biological mechanism and influencing factors of progressive liver fibrosis in BA is the basis for further improvement of its clinical prognosis. Vitamin D deficiency is widespread and severe in children with BA, and the association between vitamin $\mathrm{D}$ and liver fibrosis in chronic liver disease has been confirmed in recent years. The present study aimed to explore the intrinsic molecular biological mechanisms of vitamin $\mathrm{D}$ activation disorder and liver fibrosis in children with BA, so as to provide a new theoretical basis and therapeutic target for the antifibrosis treatment of BA.

\section{Materials and methods}

Overall study process. Ten children with BA were enrolled and 10 age-matched children (younger than 120 days of age) with choledochal cyst were selected as the control group. Clinically discarded blood samples from routine preoperative blood tests and intraoperative liver biopsy specimens from HPE procedures were collected. Serum vitamin D was detected by ELISA; serum 25 hydroxyvitamin D $(25(\mathrm{OH}) \mathrm{D})$ level was detected by electrochemiluminescence; mRNA expression of CYP2R1,CYP27A1 and vitamin D receptor (VDR) in liver tissue was detected by quantitative real-time polymerase chain reaction (qPCR); and protein expression of

\footnotetext{
${ }^{1}$ Surgical Department, Children's Hospital of Fudan University, 399 Wanyuan Road, Shanghai 201102, China. ${ }^{2}$ The Center of Laboratory Medicine, Children's Hospital of Fudan University, Shanghai 201102, China. ${ }^{3}$ Anesthesiology Department, Children's Hospital of Fudan University, Shanghai 201102, China. ${ }^{4}$ These authors contributed equally: Song Sun, Menghua Xu and Peijun Zhuang. ${ }^{\varpi}$ email: dongrui_1982@126.com; szheng@shmu.edu.cn
} 
CYP2R1 and CYP27A1 was detected by immunohistochemistry and western blotting. The above indexes were compared between the BA and control groups.

Primary hepatic stellate cells (HSCs) of children with BA $(n=10)$ were isolated by density gradient centrifugation and verified through the expression of $\alpha$-smooth muscle actin (SMA) detected by immunofluorescence assays. The effect of exogenous active vitamin $\mathrm{D}$, calcitriol $\left(1,25\right.$ dihydroxyvitamin $\left.\mathrm{D}, 1,25(\mathrm{OH})_{2} \mathrm{D}\right)$ on the expression of fibrosis-related genes such as transforming growth factor (TGF)- $\beta 1$, collagen (Col)-1 $\alpha 1$ and $\alpha$-SMA in primary HSCs was detected. The effect of calcitriol on the proliferation and migration of primary HSCs was tested by the CCK-8 assay and Transwell cell migration chambers. CYP2R1 overexpression lentivirus, CYP2R1 interference lentivirus, and negative control lentivirus were constructed by Shanghai Nuobai Biological Technology Co., Ltd. The lentiviruses were respectively transfected into QSG-7701 hepatic cells, and the coculture system of QSG-7701 and primary HSCs of BA was established. The effect of differential expression of CYP2R1 in hepatic cells on the expression of hepatic fibrosis-related genes in primary HSCs was observed.

CYP2R1 overexpression adeno-associated viruses (AAVs), CYP2R1 interference AAVs, and negative control AAVs were constructed by Shanghai Nuobai Biological Technology Co., Ltd. The common bile duct in C57BL/6 mice $(n=16)$ was ligated through laparotomy operation under general anesthesia by intraperitoneal injection of chloral hydrate. CYP2R1-overexpression AAV $\left(1 \times 10^{12} \mathrm{VP} / \mathrm{ml}, 100 \mu \mathrm{l}\right)$, CYP2R1-interference AAV $\left(1 \times 10^{12}\right.$ $\mathrm{VP} / \mathrm{ml}, 100 \mu \mathrm{l})$, negative control AAV $\left(1 \times 10^{12} \mathrm{VP} / \mathrm{ml}, 100 \mu \mathrm{l}\right)$ or $2 \mu \mathrm{g} / \mathrm{kg}$ calcitriol (positive control) was injected on the first day after surgery (4 mice per group). After 2 weeks of feeding, the mice were sacrificed by cervical dislocation, and the liver morphology and fibrosis of mice with biliary ligation were compared; in addition, the expression of genes related to liver fibrosis was tested by qPCR and western blotting and compared between the groups.

ELISA and electrochemiluminescence. Serum vitamin D concentrations in the BA group $(n=10)$ and control group $(n=10)$ were tested with a human vitamin D detection kit (Kanglang Biological Technology Co., Ltd. Shanghai, CHN). The blood samples were incubated and centrifuged to obtain sera. The sera were diluted $5 \times$, and $50 \mu \mathrm{l}$ of diluted serum was added to an enzyme coated plate, then incubated at $37^{\circ} \mathrm{C}$ for $30 \mathrm{~min}$. Subsequently, $50 \mu \mathrm{l}$ conjugate reagent was added after washing, incubated again and washed. Then $50 \mu \mathrm{l}$ chromogenic agent $\mathrm{A}$ and $50 \mu \mathrm{l}$ chromogenic agent $\mathrm{B}$ were added, and the color was developed at $37^{\circ} \mathrm{C}$ for $10 \mathrm{~min}$ in the dark. Finally, $50 \mu \mathrm{l}$ termination solution was added to each well to terminate the reaction. The absorbance of each well was measured at $450 \mathrm{~nm}$ with a microplate analyzer (Bio-Rad, USA). Serum 25(OH)D was determined according to the instructions of the Cobas E 601 Electrochemiluminescence Immunoanalyzer (Roche, Inc., USA). The sera to be tested were diluted $5 \times$, and $50 \mu$ diluted serum was incubated successively with pretreatment reagent, ruthenium-labeled vitamin $\mathrm{D}$ binding protein, streptavidin coated magnetic beads and biotin labeled $25(\mathrm{OH}) \mathrm{D}$. After incubation, the reaction liquid was transferred into the measuring chamber, and the luminous intensity was measured with a photomultiplier. The results were obtained on the basis of the calibration curve of the detector.

Isolation and culture of primary HSCs in BA. Fresh liver tissue samples (50 mg each) from patients with BA were washed with HBSS solution three times and cut into pieces. Pronase/collagenase digestion solution containing $1 \%$ DNase was added, and the digestion proceeded for $30 \mathrm{~min}$ at $37{ }^{\circ} \mathrm{C}$. The digested cell suspensions were filtered through a $70 \mu \mathrm{m}$ filter membrane, centrifuged and washed twice, then resuspended in $10 \mathrm{ml}$ GBSS/B solution containing 1\% DNase. Subsequently, $5 \mathrm{ml}$ of Nycodenz solution was added. After mixing, $1 \mathrm{ml}$ of Nycodenz solution was slowly added into the Cell-Nycodenz suspension, and centrifuged at $1380 \mathrm{~g}$ at $4{ }^{\circ} \mathrm{C}$ for $17 \mathrm{~min}$. After centrifugation, a layer of white cells was visible between the Cell-Nycodenz and GBSS/B. The intermediate layer was absorbed and resuspended with GBSS/B solution. The BA primary HSCs were obtained by further centrifugation. The primary HSCs were resuspended in DMEM containing $20 \%$ FBS and penicillin $(100 \mathrm{U} / \mathrm{ml})$-streptomycin $(0.1 \mathrm{mg} / \mathrm{ml})$ solution and incubated at $37{ }^{\circ} \mathrm{C}$ under $5 \% \mathrm{CO}_{2}$ for $24 \mathrm{~h}$. The cells were subsequently washed with PBS three times, and the culture solution was changed every 2 days. Passaging was performed when the cell density reached $90 \%$.

Establishment of a co-culture system. Hepatocytes QSG-7701 were evenly plated in the upper chamber of a six-well Transwell plate (CoStar Inc., USA) at a concentration of $4 \times 10^{5} /$ well, and culture medium containing the corresponding lentivirus (Nuobai Biological Technology Co., Ltd, Shanghai, CHN) was added for each transfection group. After transfection for $12 \mathrm{~h}$, the culture medium containing virus was discarded. RPML 1640 culture medium containing $10 \%$ fetal bovine serum was replaced for further culturing. Subsequently, the culture medium was replaced every $24 \mathrm{~h}$, and serum-free medium was used to replace the medium $72 \mathrm{~h}$ later for $12 \mathrm{~h}$ starvation treatment. The primary HSCs were plated in the lower chamber of the Transwell plate at a density of $30 \%$. The culture medium in the upper chamber was supplemented with $1 \mu \mathrm{M}$ VD and $10 \mathrm{ng} / \mathrm{ml}$ TGF- $\beta 1$ to induce fibrosis of HSCs. QSG-7701 hepatocytes were indirectly co-cultured with BA primary HSCs (separated by a $0.4 \mu \mathrm{m}$ semi-permeable membrane) for $24 \mathrm{~h}$. The primary HSCs in the lower chamber were finally collected for detection and analysis of the liver fibrosis related factors.

Quantitative real-time polymerase chain reaction (qPCR). The relative expression of CYP2R1, CYP27A1 and VDR in human liver samples; TGF- $\beta 1$, Col-1 11 and $\alpha$-SMA in primary HSCs under different culture conditions; and TGF- $\beta 1$, Col-1 $\alpha 1$, TIMP-1 and MMP- 2 in liver tissue from mice infected with AAVs was assessed by qPCR. mRNAs were extracted from $30 \mathrm{mg}$ liver tissue or $1 \times 10^{6}$ primary HSCs with a Total RNA Extraction Kit (Solarbio Science \& Technology Co., Ltd, Beijing, CHN) according to the manufacturer's recommendations. The extracted genetic material was subjected to reverse transcription with random primers by using 
a PrimeScript RT reagent Kit (Takara, Biotechnology Co., Ltd.). cDNA was amplified by PCR with a KAPA 2G Robust HotStart ReadyMix PCR Kit (Kapa Biosystems, Roche, Switzerland). The PCR primers were designed in Primer Premier 7.0 and synthesized by Sangon Bioengineering (Shanghai) Co., Ltd. PCR was performed under the following conditions: initial denaturation at $95^{\circ} \mathrm{C}$ for $10 \mathrm{~min}$, followed by 40 cycles of $95^{\circ} \mathrm{C}$ for $5 \mathrm{~s}, 60^{\circ} \mathrm{C}$ for $30 \mathrm{~s}, 72^{\circ} \mathrm{C}$ for $35 \mathrm{~s}$, and $60^{\circ} \mathrm{C}$ for $10 \mathrm{~min}$ for a final extension. The $2^{-\Delta \Delta \mathrm{C}(\mathrm{T})}$ method was used to analyze the relative changes in gene expression.

Western blot assays. The differences in mRNA levels detected by qPCR were verified at the protein level by western blot assays. Liver tissue homogenates or HSCs were collected and lysed on ice for 30 min. After ultrasonication, the samples were centrifuged at $12000 \mathrm{~g}$ for $30 \mathrm{~min}$, and the supernatant was collected. Total protein concentrations were determined with a BCA Protein Concentration Assay Kit (Enhanced) P0010S (Biyuntian Biotechnology Institute, Nantong, CHN). Equal amounts of samples were separated on 12\% SDS-polyacrylamide gels at $80 \mathrm{~V}$ for $30 \mathrm{~min}$ and $110 \mathrm{~V}$ for $60 \mathrm{~min}$. The protein bands were transferred to nitrocellulose membranes at $350 \mathrm{~mA}$ for $60 \mathrm{~min}$, and the membranes were blocked at room temperature for $120 \mathrm{~min}$. The nitrocellulose membranes were incubated with primary antibodies specific for CYP27A1 (1:1000), CYP2R1 (1:1000), TGF $\beta 1$ (1:2000), collagen1 (1:1000), TIMP1 (1:1000) and MMP2 (1:1000) (Abcam Company, UK) at $4{ }^{\circ} \mathrm{C}$ overnight. Then the nitrocellulose membranes were washed with Tris-buffered saline and Tween 20 solution. The nitrocellulose membranes were incubated with IgG-HRP secondary antibody (1:5000) at room temperature for $60 \mathrm{~min}$. Enhanced chemiluminescence assays were then performed. The gray levels of the protein bands were analyzed with Image-Pro Plus (version 7.0, Media Cybernetics, US).

Immunohistochemical assays. Liver tissues were obtained from patients with BA and immunohistochemical staining was performed on formalin-fixed tissue sections. Serial paraffin-embedded sections were placed in citrate buffer (pH6.0) and boiled in a microwave oven for $15 \mathrm{~min}$. Sections were treated with 3\% hydrogen peroxide for 10 min at room temperature and blocked with 5\% BSA for $30 \mathrm{~min}$. Sections were stained with rabbit anti-CYP27A1 and rabbit anti-CYP2R1 antibodies (1:200, Abcam, UK) overnight, followed by incubation biotin labeled secondary antibodies for $30 \mathrm{~min}$ and diaminobenzidine (DAB) for $1 \mathrm{~min}$. Immunostaining results were evaluated by calculation of the mean density with Image-Pro Plus (version 7.0, Media Cybernetics, US).

CCK-8 experiments. A total of 6000 HSCs were seeded in 96-well plates containing medium with or without $200 \mathrm{nM}$ calcitriol. Then $10 \mu \mathrm{l} \mathrm{CCK8}$ reagent was added at $0 \mathrm{~h}, 24 \mathrm{~h}, 48 \mathrm{~h}$ or $72 \mathrm{~h}$. After the plates were incubated for 2 more hours, the absorbance at $450 \mathrm{~nm}$ was measured with a microplate analyzer (Biochrom Anthos, $\mathrm{UK})$. The cell proliferation inhibition rate was calculated as follows: IOD at each time point/IOD at $0 \mathrm{~h}-1$.

Transwell cell migration assays. The upper chamber of a Transwell system was seeded with $200 \mu \mathrm{l}$ HSC suspension at a density of $1 \times 10^{5} / \mathrm{ml}$ in serum-free medium, and the lower chamber was filled with $600 \mu \mathrm{l}$ complete medium with or without $200 \mathrm{nM}$ calcitriol. After $24 \mathrm{~h}$ of culture, the lower cells were fixed with $4 \%$ paraformaldehyde for $30 \mathrm{~min}$ and stained with $1 \%$ crystal violet for $10 \mathrm{~min}$. The plates were observed under a microscope and counted in five fields.

Statistical analysis. The statistical software SPSS (version 20.0) was used for data analysis, and SPSS software and GraphPad Prism 8 software were used to produce charts. The measurement data were first tested for normality, and data with a normal distribution were expressed as the mean \pm standard error of the mean (SEM). The t-test was used for comparison between two groups, one-way ANOVA was used for comparison between multiple groups of data, and Bonferroni correction was used for pairwise comparison. The statistical significance was set at $P<0.05$.

All clinical studies and animal experimental protocols in this study were approved by the Ethics Committee of Children's Hospital of Fudan University. All methods used in this study were performed in accordance with the relevant guidelines and regulations both for animal experiment and human involvement. Informed consent was obtained from the parents or legal guardians of all involved participants.

\section{Results}

Basic clinical data. Ten children were enrolled in the BA and control groups. The general conditions and the results of laboratory examination of the children are listed in Table 1 . There was no significant difference in age, sex, body weight, hemoglobin, international standardized ratio, alkaline phosphatase, and glutamyl transpeptidase between the two groups. The total bilirubin, direct bilirubin, alanine transaminase, and aspartate transaminase in the BA group were higher than in the control group $(P<0.05)$. Creatinine was slightly lower in the BA group than in the control group $(P<0.05)$.

Level of 25(OH)D and ratio of $25(\mathrm{OH}) \mathrm{D} /$ vitamin $\mathrm{D}$ in the BA group were significantly lower than in the control group. The serum levels of vitamin D were detected by ELISA: $1386.0 \pm 153.1$ and $1305.3 \pm 244.8 \mathrm{ng} / \mathrm{mL}$ in the control and BA groups, respectively. $25(\mathrm{OH}) \mathrm{D}$ was detected by electrochemiluminescence. The level of $25(\mathrm{OH}) \mathrm{D}$ in the control and BA groups was $24.3 \pm 6.1$ and $9.3 \pm 4.9 \mathrm{ng} / \mathrm{mL}$, respectively. $25(\mathrm{OH}) \mathrm{D}$ level in the BA group was significantly lower than that in the control group $(P<0.001)$ (Fig. 1). The ratio of $25(\mathrm{OH}) \mathrm{D}$ to vitamin $\mathrm{D}$ in serum was used to evaluate the capacity of 25 hydroxylation during vitamin $\mathrm{D}$ activation. The ratio of $25(\mathrm{OH}) \mathrm{D} /$ vitamin $\mathrm{D}$ was $1.75 \pm 0.44 \%$ in the control group, which was significantly 


\begin{tabular}{|l|l|l|l|}
\hline & BA group $(\mathbf{n}=10)$ & Control group $(\mathbf{n}=10)$ & $P$ value \\
\hline Age $($ days $)$ & $59.4 \pm 17.4$ & $57.6 \pm 32.0$ & 0.878 \\
\hline Gender $(\mathrm{M} / \mathrm{F})$ & $3 / 7$ & $5 / 5$ & 0.650 \\
\hline Weight $(\mathrm{kg})$ & $4.6 \pm 0.3$ & $4.7 \pm 0.9$ & 0.846 \\
\hline TB $(\mu \mathrm{mol} / \mathrm{L})$ & $175.5 \pm 66.9$ & $87.3 \pm 54.1$ & $0.005^{*}$ \\
\hline DB $(\mu \mathrm{mol} / \mathrm{L})$ & $115.3 \pm 47.4$ & $41.2 \pm 24.1$ & $0.001^{*}$ \\
\hline ALT $(\mathrm{IU} / \mathrm{L})$ & $186.0 \pm 186.9$ & $60.9 \pm 41.9$ & $0.044^{*}$ \\
\hline AST $(\mathrm{IU} / \mathrm{L})$ & $242.7 \pm 166.5$ & $81.1 \pm 45.3$ & $0.014^{*}$ \\
\hline ALP $(\mathrm{IU} / \mathrm{L})$ & $587.4 \pm 289.7$ & $533.4 \pm 242.4$ & 0.600 \\
\hline GGT $(\mathrm{IU} / \mathrm{L})$ & $454.3 \pm 289.7$ & $544.9 \pm 440.2$ & 0.594 \\
\hline Hb $(\mathrm{g} / \mathrm{L})$ & $99.2 \pm 11.8$ & $105.8 \pm 18.0$ & 0.350 \\
\hline INR & $1.0 \pm 0.1$ & $1.1 \pm 0.2$ & 0.521 \\
\hline Crea $(\mu \mathrm{mol} / \mathrm{L})$ & $19.4 \pm 1.7$ & $24.9 \pm 5.5$ & $0.012^{*}$ \\
\hline
\end{tabular}

Table 1. General information and laboratory test results of children enrolled in the clinical study. $T B$ total bilirubin, $D B$ direct bilirubin, $A L T$ alanine aminotransferasem $A S T$ aspartate transaminase, $A L P$ alkaline phosphatase, GGT $\gamma$-glutamyl transpeptidase, $H b$ hemoglobin, INR international standardized ratio, $C R E A$ creatinine. Asterisks denote statistically significant differences (Student's t test: ${ }^{\star} \mathrm{p}<0.05$ ).

$25(\mathrm{OH}) \mathrm{D} \rightarrow-$ Vitanmin D

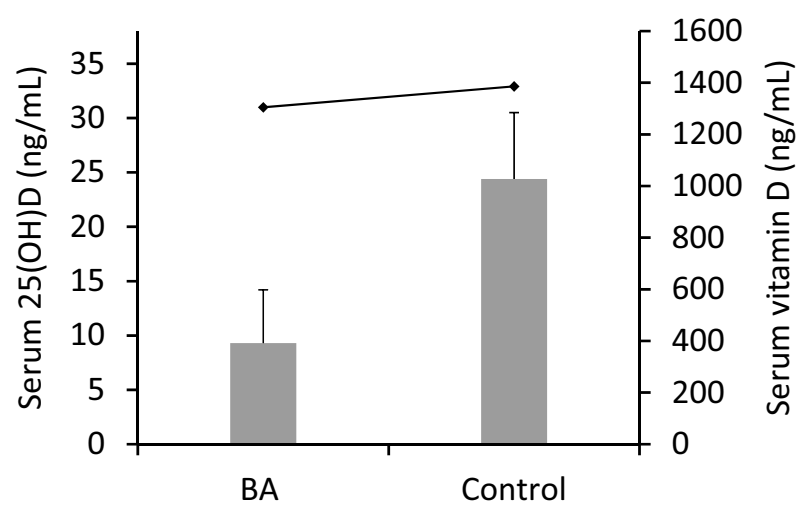

Figure 1. Serum levels of vitamin D in the BA and control groups were similar, while $25(\mathrm{OH}) \mathrm{D}$ level in the BA group was significantly lower than in the control group, thus, suggesting that conversion of vitamin $\mathrm{D}$ to $25(\mathrm{OH})$ D was impaired in children with BA.

higher than $0.72 \pm 0.40 \%$ in the BA group $(P<0.001)$. This suggested that the 25 hydroxylation ability of vitamin $\mathrm{D}$ in the BA group was impaired.

Expression of CYP2R1 and CYP27A1 in liver tissue of children with BA group was significantly lower than in the control group. To verify the vitamin D activation disorder in BA, we detected the expression of CYP2R1 and CYP27A1, which are important hydroxylases that convert vitamin D to $25(\mathrm{OH}) \mathrm{D}$ in the liver. qPCR showed that $\mathrm{mRNA}$ expression of CYP2R1 and CYP27A1 in the BA group was significantly lower than in the control group (CYP2R1: $0.51 \pm 0.28$ vs. $1.27 \pm 0.63, P=0.004$; CYP27A1: $0.41 \pm 0.16$ vs. $1.09 \pm 0.57$, $P=0.004$ ) (Fig. 2), and no significant difference was detected in the expression of VDR mRNA between the two groups $(0.61 \pm 0.39$ vs. $0.53 \pm 0.43, P=0.698)$. Immunohistochemical analysis of liver tissue sections showed that the expression of CYP2R1 and CYP27A1 proteins were strongly positive in liver tissue of the control group, but slightly positive in the BA group. The difference was significant: integrated option density (IOD)/area CYP2R1: $0.036 \pm 0.020$ vs. $0.069 \pm 0.011, P=0.002$; CYP27A1: $0.033 \pm 0.016$ vs. $0.071 \pm 0.015, P<0.001$ ) (Fig. 2 ). Western blotting verified the expression of CYP2R1 and CYP27A1, which confirmed that expression of CYP2R1 and CYP27A1 proteins in liver tissues of patients with BA was significantly lower than in the control group (CYP2R1: $0.67 \pm 0.28$ vs. $1.13 \pm 0.43, P=0.026$; CYP27A1: $0.41 \pm 0.15$ vs. $0.68 \pm 0.27, P=0.035$ ) (Fig. 2 ).

Culture and identification of primary HSCs of patients with BA. Primary HSCs isolated by density gradient centrifugation were spherical cells with high refraction under inverted microscopy, and lipid droplets were clearly seen in the cytoplasm. After $24 \mathrm{~h}$ of culture, most of the cells began to grow adherently, and a few cells began to extend their tentacles. After 2-3 days of culture, most of the cells showed polycephalous pseu- 

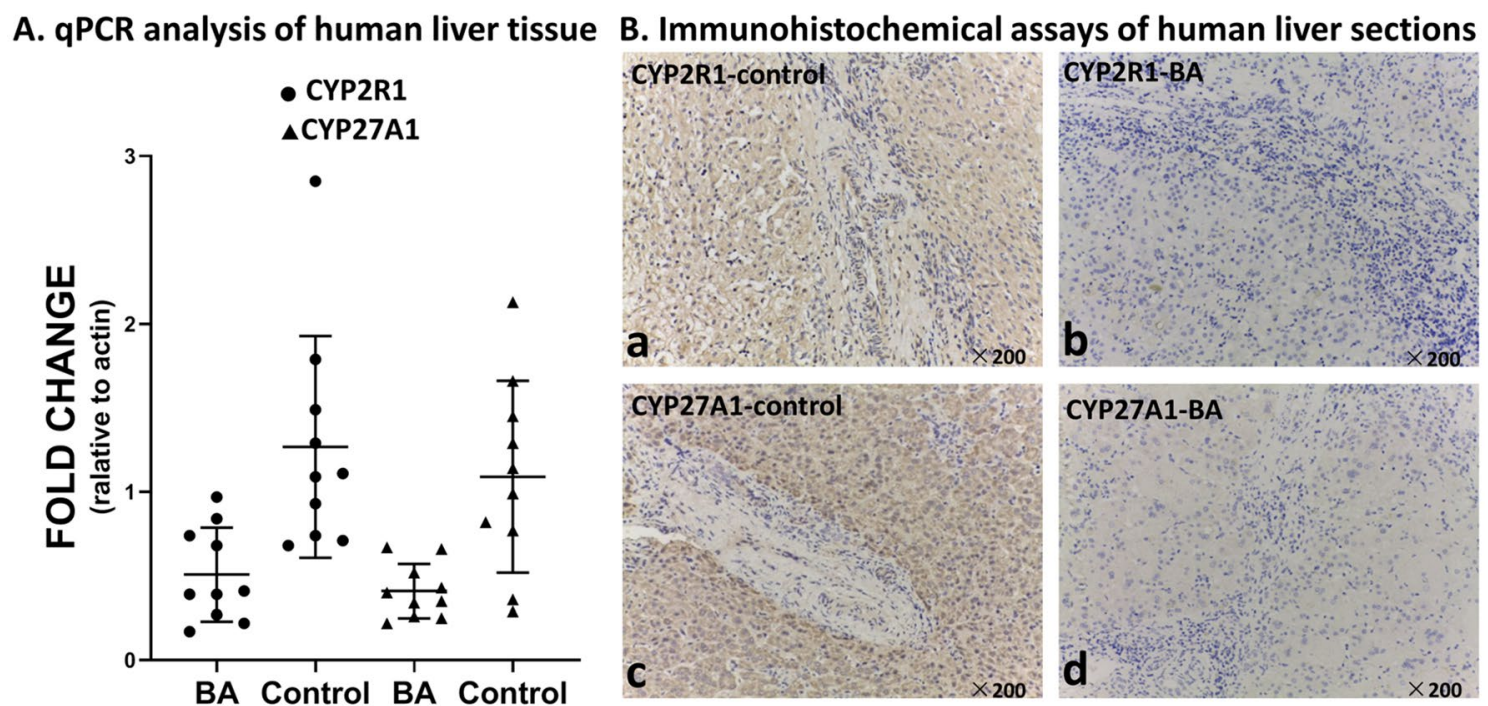

\section{Western blot assays of CYP2R1 and CYP27A1 in human liver tissue}

BA

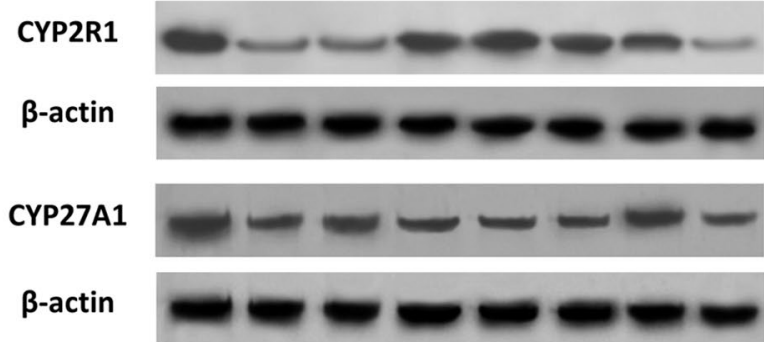

Control

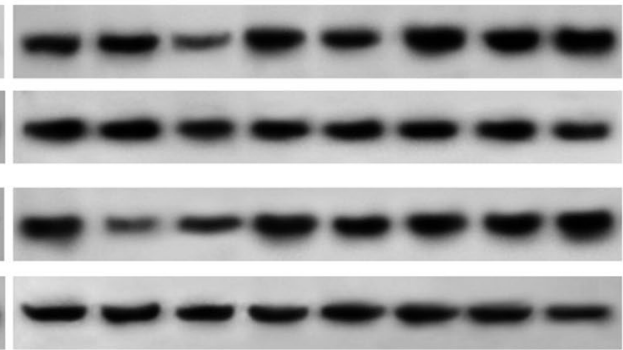

Figure 2. Expression of 25-hydroxylase CYP2R1 and CYP27A1 in liver tissue of BA and control groups. (A) Dot plot of mRNA levels of CYP2R1 and CYP27A1. (B) The expression of CYP2R1 and CYP27A1 in the BA and control groups detected by immunohistochemistry. Brown staining represents expression of CYP2R1 and CYP27A1. $a$ and b show expression of CYP2R1 in the control and BA groups, and $\mathrm{c}$ and $\mathrm{d}$ show expression of CYP2R1 in the control and BA groups, respectively. (C) The expression of CYP2R1 and CYP27A1 in the BA and control groups detected by western blotting.

dopods or typical HSC morphology (Fig. 3). On the seventh day of culture, the lipid droplets in the cytoplasm disappeared completely, and the cells became spindle-shaped. After 12-14 days of culture, the cells grew into monolayers. Immunofluorescence assays showed that the percentage of $\alpha$-SMA-positive cells was $97 \%$ on day 7 of culture (Fig. 3).

Calcitriol inhibits expression of fibrosis-related genes, proliferation and migration of primary HSCs from patients with BA in vitro. Primary HSCs of patients with BA were cultured in vitro with calcitriol at 100, 200 and $400 \mathrm{nM}$ for $24 \mathrm{~h}$. qPCR indicated that expression of TGF- $\beta 1$, Col-1 $\alpha 1$ and $\alpha$-SMA was decreased after addition of calcitriol, and the decrease was most significant with $200 \mathrm{nM}$ calcitriol (Table 2).

The proliferation of primary HSCs treated with $200 \mathrm{nM}$ calcitriol for 24,48 and $72 \mathrm{~h}$ was lower than that of untreated HSCs $(0.34 \pm 0.13$ vs. $0.46 \pm 0.09, P<0.01 ; 0.88 \pm 0.15$ vs. $1.01 \pm 0.11, P<0.01 ; 1.51 \pm 0.13$ vs. $1.73 \pm 0.10$, $P<0.01)$. The Transwell assay showed that the migrated cell count of the untreated group was $382 \pm 51$, and that of the $200 \mathrm{nM}$ calcitriol group was $223 \pm 76$, which was a significant difference $(P<0.01)$ (Fig. 4$)$. These results suggest that calcitriol can inhibit the proliferation and migration of HSCs.

Construction of CYP2R1 lentivirus and validation of hepatocyte transfection effect. CYP2R1overexpression lentivirus (CL1674-PDS237_PL-CMV-GFP-CYP2R1) and CYP2R1-interference lentivirus (CL1676-PDS126_PL6.3-shRNA-GFP-CYP2R1-932) vectors were constructed with titers of $4.5 \times 10^{8} \mathrm{TU} / \mathrm{mL}$. QSG-7701 hepatocytes were transfected with CYP2R1-overexpression lentivirus, CYP2R1-interference lentivirus or negative control lentivirus. qPCR showed that the expression of CYP2R1 mRNA in the CYP2R1 overexpression group was significantly higher than in the negative control group $(9.39 \pm 0.34$ vs. $1.0 \pm 0.04, P<0.001)$, and expression in the CYP2R1-interference group was significantly lower than in the negative control group $(0.37 \pm 0.06$ vs. $1.0 \pm 0.04, P<0.001)$. These results indicated that CYP2R1-overexpression lentivirus increased expression of CYP2R1, while CYP2R1-interference lentivirus reduced expression of CYP2R1. 


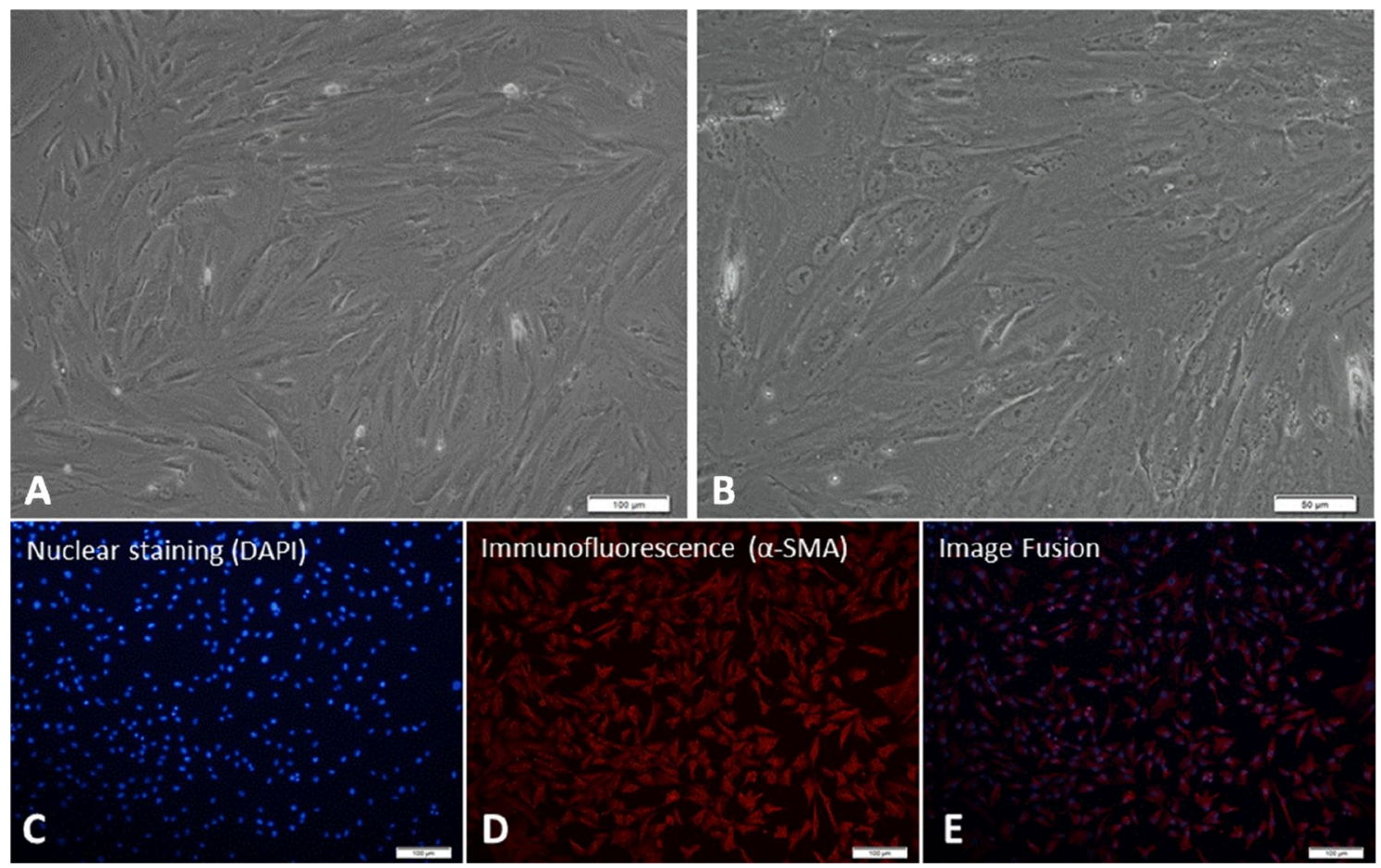

Figure 3. (A) Primary HSCs isolated from BA patients showed typical morphology $(100 \times)$ after 3 days of culture. (B) Local magnification shows intracellular lipid droplets (200x). Expression of $\alpha$-SMA in primary HSCs of BA was detected by immunofluorescence assay. (C) Nuclear staining (DAPI). (D) Cytoplasm showed red fluorescence indicating positive $\alpha$-SMA expression. (E) Fusion images: the positive rate of $\alpha$-SMA was $97 \%$ after counting.

\begin{tabular}{|l|l|l|l|l|}
\hline & Untreated group & $\mathbf{1 0 0} \mathbf{~ n M}$ group & $\mathbf{2 0 0} \mathbf{n M}$ group & 400 nM group \\
\hline TGF- $\beta 1$ & $1.00 \pm 0.27$ & $0.73 \pm 0.16^{*}$ & $0.53 \pm 0.15^{*}$ & $0.56 \pm 0.18^{*}$ \\
\hline Col-1 $\alpha 1$ & $1.00 \pm 0.16$ & $0.90 \pm 0.22^{*}$ & $0.71 \pm 0.14^{*}$ & $0.76 \pm 0.11^{*}$ \\
\hline$\alpha-S M A$ & $1.00 \pm 0.17$ & $0.97 \pm 0.28$ & $0.59 \pm 0.06^{*}$ & $0.66 \pm 0.20^{*}$ \\
\hline
\end{tabular}

Table 2. Effects of calcitriol at different concentrations on the mRNA expression of TGF- $\beta 1$, Col- $1 \alpha 1$ and a-SMA in pHSC. ${ }^{*}$ Compared with the untreated group, $P<0.05$.
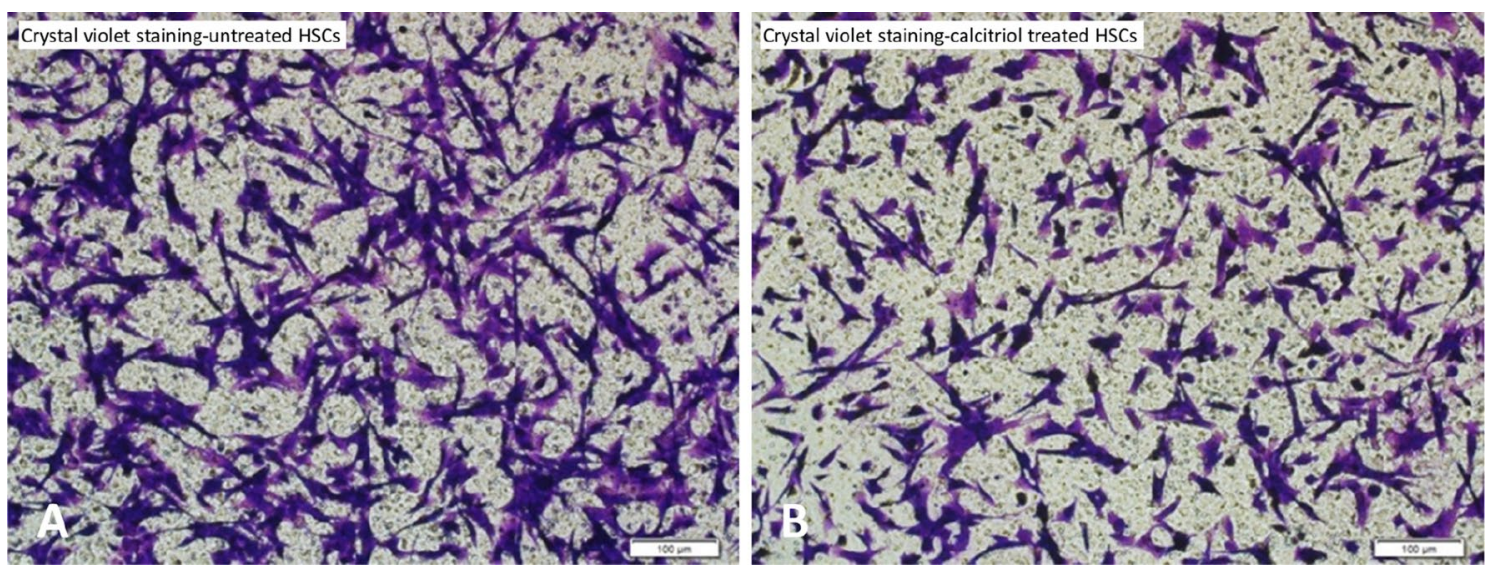

Figure 4. The Transwell assay showed that the migrated cell count of the untreated group (A) was higher than that of the $200 \mathrm{nM}$ calcitriol treatment group $(\mathbf{B})(P<0.01)$. 


\title{
A. Western blot assays of cocultured HSCs of BA
}

\begin{tabular}{|c|c|c|c|c|c|c|c|c|c|}
\hline & 1 & 2 & 3 & 4 & 5 & 6 & 7 & 8 & 9 \\
\hline TGF- $\beta 1$ & 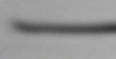 & & $=$ & & & & $=$ & & $=$ \\
\hline Col-1 $\alpha 1$ & $=$ & 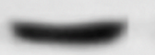 & 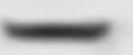 & 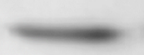 & $=$ & $\longrightarrow$ & $=$ & 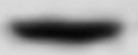 & 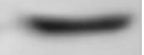 \\
\hline TIMP-1 & $\longrightarrow$ & 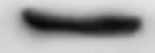 & 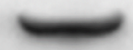 & $\longrightarrow$ & 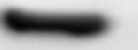 & 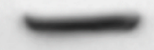 & 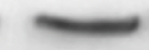 & 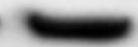 & 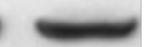 \\
\hline MMP-2 & 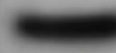 & 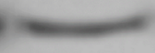 & 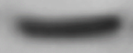 & 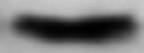 & 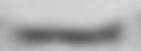 & 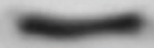 & s & $\mathrm{men}$ & 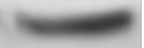 \\
\hline$\beta$-actin & & & & & & & & & \\
\hline
\end{tabular}

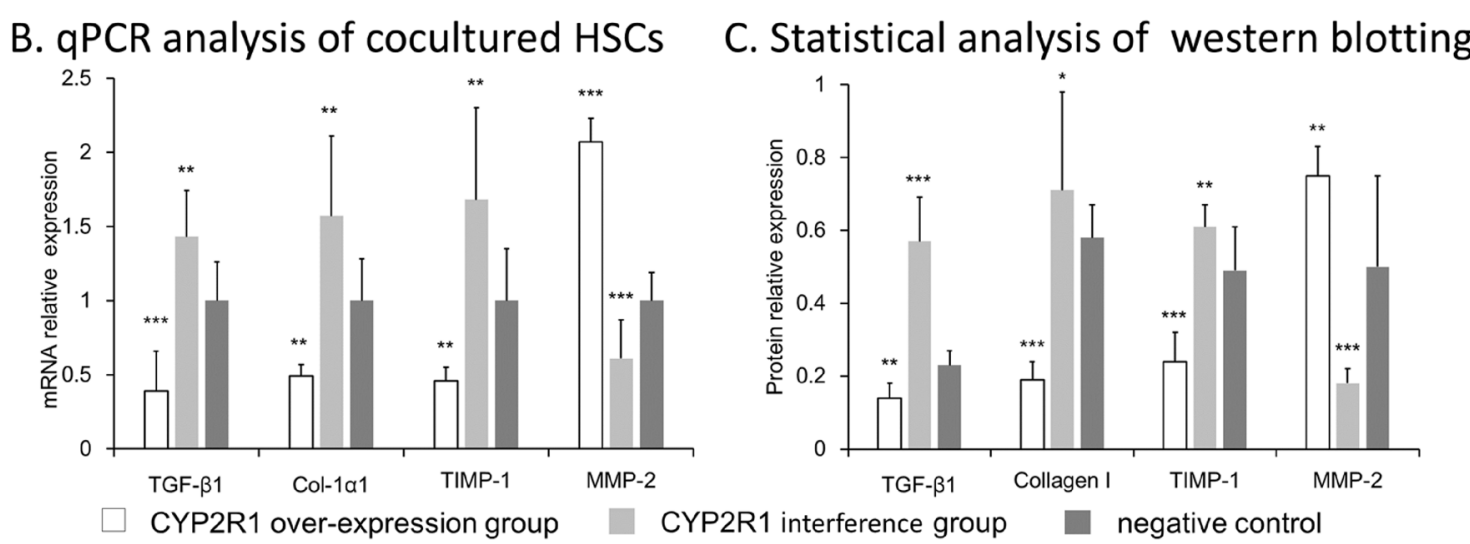

Figure 5. Regulation of expression of CYP2R1 in hepatocytes can change mRNA and protein expression of fibrosis-related factors in cocultured primary HSCs of BA. (A) protein expression of fibrosis-related factors in CYP2R1-overexpression group (columns 1, 4 and 7), CYP2R1-interference group (columns 2, 5 and 8) and negative control group (columns 3, 6 and 9). (B,C) statistical results of qPCR and western blotting detection of fibrosis-related factors in each intervention group.

\begin{abstract}
Upregulation of expression of CYP2R1 in hepatocytes reduced mRNA and protein expression of fibrosis-related factors in cocultured primary HSCs of BA. Primary HSCs of patients with BA were cocultured with CYP2R1-overexpression QSG-7701 hepatocytes, CYP2R1-interference QSG-7701 hepatocytes, or QSG-7701 hepatocytes (negative control). After incubation for $48 \mathrm{~h}$, primary HSCs of BA in the coculture system were collected and assayed by qPCR. mRNA expression of TGF- $\beta 1$, Col-1a1 and TIMP-1 in the CYP2R1 overexpression group was lower than in the negative control group $(P<0.001)$, and higher in the CYP2R1 interference group than in the negative control group $(P<0.01)$. mRNA expression of MMP-2 in the CYP2R1-overexpression group was higher than in the negative control group $(P<0.001)$, and was lower in the CYP2R1-interference group than in the negative control group $(P<0.01)$ (Fig. 5). Western blotting showed that expression of these liver-fibrosis-related factors at the protein level also complied with this trend (Fig. 5). These results indicated that overexpression of CYP2R1 in hepatocytes decreased expression of TGF- $\beta 1$, Col-1a1 and TIMP-1, and increased expression of MMP-2 in HSCs, while low expression of CYP2R1 in hepatocytes increased expression of TGF- $\beta 1$, Col-1 $\alpha 1$ and TIMP- 1 , and decreased expression of MMP- 2 .
\end{abstract}

Downregulation of CYP2R1 expression in liver of mice with biliary obstruction aggravated cirrhosis. CYP2R1-overexpression AAV (CL1831-PDS272_PAAV-CMV-GFP-CYP2R1) and CYP2R1-interference AAV (CL1842-PAAV-U6-CYP2R1-shRNA-932) vectors were constructed with titers of $1 \times 10^{12} \mathrm{VP} / \mathrm{mL}$. The first day after bile duct ligation of C57BL/6 mice, CYP2R1-overexpression AAV, CYP2R1-interference AAV, negative control AAV or $2 \mu \mathrm{g} / \mathrm{kg}$ calcitriol (positive control) was injected. The mice were fed for 2 more weeks. The liver morphology was observed as follows: the liver of the negative control group was enlarged, with tight, brown and a slightly hard liver capsule; the liver of the CYP2R1-overexpression AAV group and the positive control group was ruddy, soft, smooth and the liver capsule was not tight. In the CYP2R1-interference AAV group, the liver was enlarged with dark color, hard texture and nodular protuberance on the surface. Masson staining of liver tissue showed that there were more blue collagen fibers deposited in liver tissue of the CYP2R1-interference group, extending outward from portal areas and their surroundings, and the fibers were thicker and the staining 


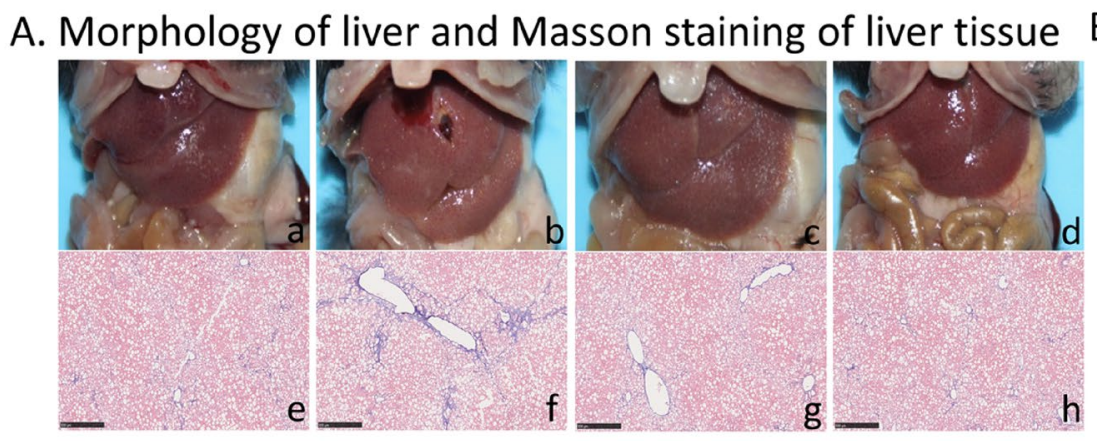

\section{B. mRNA expression of CYP2R1 and serum $25(\mathrm{OH}) \mathrm{D}$ level}

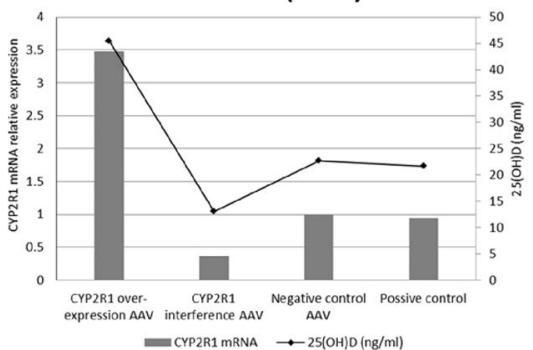

C. Western blot assays of liver tissue in each group

\begin{tabular}{|c|c|c|c|c|}
\hline & $\begin{array}{c}\text { CYP2R1 over- } \\
\text { expressed AAV group }\end{array}$ & $\begin{array}{c}\text { CYP2R1 interference } \\
\text { AAV group }\end{array}$ & Negative control & Positive control \\
\hline TGF- $\beta 1$ & $-1=$ & $=0$ & $-\infty-\infty$ & $1-\cdots$ \\
\hline Collagen-I & $--\cdots$ & $-\infty$ & $-\omega-\infty$ & $-\cdots$ \\
\hline TIMP-1 & -1 & & $=0$ & $-\infty-1=$ \\
\hline MMP-2 & $-\infty=$ & $-\cdots$ & $-\cdots-$ & $m-\infty$ \\
\hline$\beta$ & & & & \\
\hline
\end{tabular}

D. qPCR analysis of liver tissue in each group

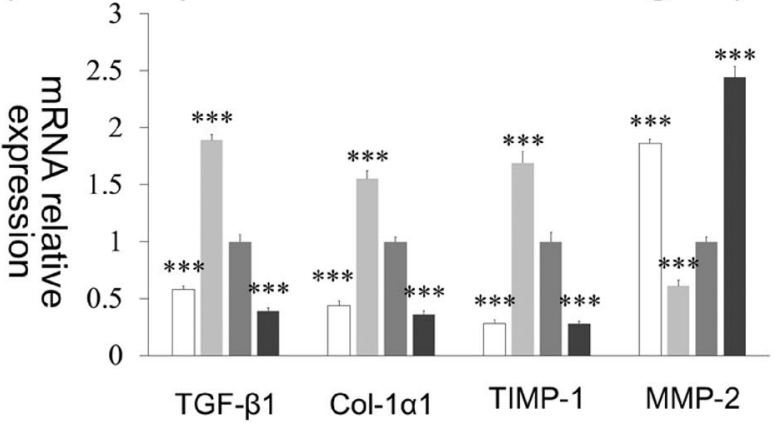

E. Statistical analysis of western blotting

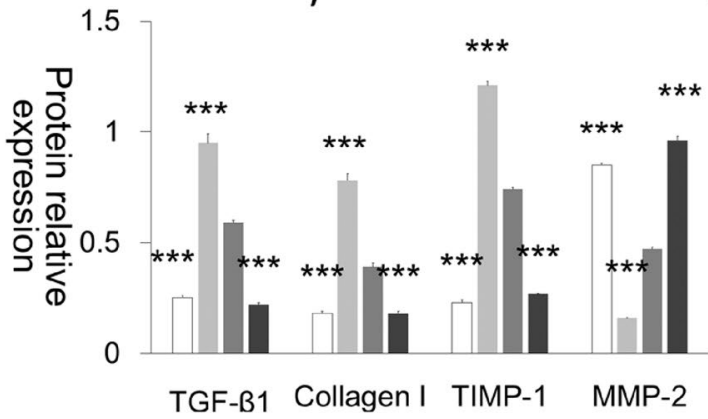

CYP2R1 over-expressed AAV group $\square$ CYP2R1 interference AAV group $\square$ Negative control $\square$ Positive control

Figure 6. (A) morphology of liver and Masson staining of liver tissue: the liver of the CYP2R1-overexpression AAV group (a) and positive control group (d) was ruddy, soft, smooth and the liver capsule was not tense. In the CYP2R1-interference AAV group (b), the liver was enlarged with dark color, hard texture and nodular protuberance on the surface. The liver of negative control group (c) was enlarged, with tight, brown and slightly hard liver capsule. Masson staining of liver tissue of mice showed that there were more blue collagen fibers deposited in liver tissue of the CYP2R1-interference group (f), extending outward from around the vascular region, and the fibers were thicker and the staining was darker. The CYP2R1-overexpression AAV group (a) and positive control group (g) showed less blue collagen deposition in liver tissues. (B) mRNA expression of CYP2R1 and serum 25(OH)D level in each intervention group. (C) protein level of the liver-fibrosis-related factors in each intervention group detected by western blotting. $(\mathbf{D}, \mathbf{E})$ statistical results of qPCR and western blotting detection of liver-fibrosis-related factors in each intervention group.

was darker than in the other groups. The CYP2R1-overexpression group and calcitriol-positive control group showed less blue collagen deposition in liver tissue (Fig. 6).

Overexpression or interference of the CYP2R1 gene affected 25(OH)D level through changing CYP2R1 expression. qPCR showed that the expression of CYP2R1 mRNA in the CYP2R1-overexpression AAV group was higher than that in the negative control group $(P<0.001)$, and expression in the CYP2R1interference AAV group was lower than in the negative control group $(P<0.001)$. This indicated that gene trans- 
fection successfully altered expression of CYP2R1. The 25(OH)D level of mice in the CYP2R1-overexpression AAV group was higher than in the negative control group $(P<0.001)$, and the $25(\mathrm{OH}) \mathrm{D}$ level in the CYP2R1interference AAV group was lower than in the negative control group $(P<0.01)$. This shows that CYP2R1 overexpression can lead to an increase in $25(\mathrm{OH}) \mathrm{D}$ levels, and downregulation of CYP2R1 can lead to a decrease in 25(OH)D levels (Fig. 6).

Overexpression or interference of the CYP2R1 gene affected expression of mRNA and protein levels of liver fibrosis-related factors in mice with biliary ligation. qPCR showed that mRNA expression of TGF- $\beta 1$, Col-1 $\alpha 1$ and TIMP-1 in the CYP2R1-overexpression AAV group and calcitriol-positive control group was lower than in the negative control group $(P<0.001)$, and expression in the CYP2R1-interference AAV group was higher than in the negative control group $(P<0.01)$. These results suggested that increasing expression of CYP2R1 or adding exogenous calcitriol reduced the expression of liver-fibrosis-related genes, whereas decreasing expression of CYP2R1 increased expression of liver-fibrosis-related genes. In contrast, the expression of antifibrosis factor MMP-2 mRNA was higher in the CYP2R1-overexpression AAV group and calcitriol positive control group than in the negative control group $(P<0.001)$. Expression in the CYP2R1-interference group was lower than in the negative control group $(P<0.001)$, indicating that CYP2R1 or exogenous calcitriol increased the expression of MMP-2 (Fig. 6). Western blotting verified the expression at the protein level of the above hepatic-fibrosis-related factors, and showed that the changes in each protein were consistent with the mRNA levels (Fig. 6).

\section{Discussion}

BA is the most common biliary obstructive disease in infants, and the most common cause of jaundice, with an incidence of $1 / 8000-18,000^{1,2}$. BA is a fibrous inflammatory disease of the intrahepatic and extrahepatic bile duct tree, characterized by intrahepatic and extrahepatic bile duct atresia and progressive hepatic fibrosis. The liver fibrosis of $\mathrm{BA}$ is earlier and more severe than any other infant cholestatic disease ${ }^{3-7}$; therefore, the presence of cirrhosis is often used for differential diagnosis of BA. Liver fibrosis may be the primary pathogenic factor in the pathological mechanism of BA, rather than biliary cirrhosis secondary to cholestasis alone. Although liver fibrosis has traditionally been considered an irreversible process, it is now believed that liver fibrosis is a reversible pathological event, especially in children, if there is an underlying mechanism for timely intervention to prevent liver fibrosis. Therefore, the treatment of liver fibrosis after HPE is important and deserves further study to avoid liver transplantation. It is now gradually realized that without a clear understanding of the mechanism and influencing factors of liver fibrosis, it is difficult to achieve further breakthroughs in the treatment of autologous liver of BA. The mechanism of liver fibrosis in BA has been studied extensively, mainly focusing on immune regulation disorder $^{8-10}$, viral infection ${ }^{11,12}$, and excessive release of inflammatory factors ${ }^{1}$. These factors may play a role in aggravating cirrhosis to some extent or in some patients, but there is still no consensus on the mechanism of the formation or aggravation of cirrhosis in BA, which may be a result of the combined action of multiple factors.

The main source of vitamin D is the daily diet, and vitamin D absorbed from food is first converted to $25(\mathrm{OH})$ $\mathrm{D}$ by hydroxylation of CYP2R1 and CYP27A1 in the liver. It is then hydroxylated to $1,25,(\mathrm{OH})_{2} \mathrm{D}$ in the presence of CYP27B1 in the kidneys. Both $25(\mathrm{OH}) \mathrm{D}$ and $1,25,(\mathrm{OH})_{2} \mathrm{D}$ have biological activity. $1,25,(\mathrm{OH})_{2} \mathrm{D}$ is the final active product of vitamin D metabolism, which has higher biological activity than $25(\mathrm{OH}) \mathrm{D}$ has. Activated vitamin $\mathrm{D}$ can bind to the vitamin D receptor (VDR) and then play a biological role. VDR is a member of the nuclear receptor superfamily, and its classical biological effects are mainly to maintain calcium homeostasis and calcium deposition in bone. In recent years, vitamin $\mathrm{D}$ has been found to have antifibrotic effects in lung, kidney and other tissues ${ }^{13-18}$. VDR is not expressed in liver tissue, so the role of vitamin D in liver fibrosis has not been studied in depth for a long time. However, the latest studies have found that VDR is expressed in nonparenchymal liver cells ${ }^{19}$, such as HSCs, which suggests that vitamin D is a regulatory factor in liver fibrosis.

Vitamin D deficiency is common in liver diseases, especially in the case of cirrhosis, but it is difficult to determine the causal relationship between vitamin D deficiency and liver diseases. It is generally believed that absorption and activation of vitamin $\mathrm{D}$ are impaired due to liver dysfunction in cirrhosis, although there are few studies on the effect of vitamin D deficiency on cirrhosis. The studies of patients with chronic liver disease have shown that low serum $25(\mathrm{OH}) \mathrm{D}$ is strongly associated with severe cirrhosis and low responsiveness to treatment ${ }^{20-23}$. Vitamin D deficiency can aggravate the degree of liver fibrosis in patients with liver disease ${ }^{20,23}$, while supplementation with vitamin D can improve liver fibrosis in patients with chronic liver disease ${ }^{24,25}$. Vitamin D deficiency or VDR gene polymorphism increases the risk of cirrhosis ${ }^{26,27}$. These results suggest that vitamin D plays an important role in the occurrence of liver fibrosis. In vitro and in vivo experimental studies have found that vitamin D can reduce the proliferation of HSCs, inhibit expression of profibrosis genes such as Col-1 1 1 and TIMP-1, and promote expression of antifibrosis genes such as MMP9 ${ }^{28-30}$. VDR gene knockout can lead to primary liver fibrosis ${ }^{31}$. Based on the above studies, in the case of severe liver disease, there may be a vicious cycle of aggravation of liver fibrosis and impairment of vitamin D absorption and activation, which play a role in the progression of cirrhosis ${ }^{32}$.

As early as 1979, the lack of $25(\mathrm{OH}) \mathrm{D}$ in children with BA was noted by Japanese researchers ${ }^{33}$. However, in the following decades, this issue did not attract widespread attention or in-depth research, and clinicians took it for granted that it was due to the absorption deficiency of fat-soluble vitamins caused by reduced bile. In recent years, as more studies have gradually revealed the internal relationship between vitamin D deficiency and liver fibrosis, researchers have begun to pay attention to this problem. $\mathrm{Ng}$ et al. ${ }^{34}$ detected the pre-HPE $25(\mathrm{OH}) \mathrm{D}$ level in 92 children with $\mathrm{BA}$, and found that $98.9 \%$ of the children had $25(\mathrm{OH}) \mathrm{D}$ deficiency or insufficiency, and only one $(1.1 \%)$ had a normal level of $25(\mathrm{OH}) \mathrm{D}$. Zhuang et al. ${ }^{35}$ examined the $25(\mathrm{OH}) \mathrm{D}$ level before HPE of 161 BA cases, and found that $96.3 \%$ of the children had $25(\mathrm{OH}) \mathrm{D}$ deficiency or insufficiency. However, these 
studies confirmed deficiency of $25(\mathrm{OH}) \mathrm{D}$ in children with $\mathrm{BA}$, but did not further investigate the cause of that deficiency and its effect on liver lesions. Considering that the current clinical evaluation of vitamin D status is mostly through the detection of serum $25(\mathrm{OH}) \mathrm{D}$ level, and the current vitamin D supplement program is mostly oral vitamin $\mathrm{D}$, oral intake of vitamin $\mathrm{D}$ cannot improve $25(\mathrm{OH}) \mathrm{D}$ deficiency, and serum $25(\mathrm{OH}) \mathrm{D}$ level does not reflect the extent of vitamin D deficiency in cases of vitamin D hydroxylation disorders.

In order to comprehensively evaluate the levels of vitamin $\mathrm{D}$ and $25(\mathrm{OH}) \mathrm{D}$ in vivo, we detected the serum levels of vitamin D and 25(OH)D in the BA and control groups. The level of vitamin D in BA was lower than in the control group, while the level of $25(\mathrm{OH}) \mathrm{D}$ was significantly lower than in the control group. The ratio of $25(\mathrm{OH}) \mathrm{D} /$ vitamin $\mathrm{D}$ was used to reflect the efficiency of vitamin $\mathrm{D}$ transformation to $25(\mathrm{OH}) \mathrm{D}$, and the results also showed that there was a significant reduction in vitamin $\mathrm{D}$ activation rate in the BA group. It has been shown that CYP2R1 and CYP27A1 are key enzymes in the first step of hydroxylation of vitamin D, in which CYP2R1 plays a major role in the transformation of vitamin $\mathrm{D}$ to $25(\mathrm{OH}) \mathrm{D}^{36-38}$. CYP2R1 is expressed only in the liver, so that is the only site for the initial hydroxylation of vitamin D. In the present study, CYP2R1 expression was detected in the liver of children with BA, and the results showed that CYP2R1 expression was significantly decreased. Therefore, the decreased expression of CYP2R1 was the main cause of 25(OH)D deficiency, rather than vitamin D malabsorption, which could explain why $25(\mathrm{OH}) \mathrm{D}$ deficiency was difficult to be corrected by oral supplementation of vitamin D in clinical practice.

As previously mentioned, active vitamin D deficiency can aggravate liver fibrosis in liver disease, and children with BA have significant 25(OH)D deficiency and vitamin D activation disorder. Whether the active vitamin D deficiency and activation disorder in BA are involved in the pathological process of liver fibrosis has not been researched to date, even though a correlation between $25(\mathrm{OH}) \mathrm{D}$ deficiency and liver fibrosis in BA has been confirmed in several clinical studies. Zhuang et al. ${ }^{35}$ examined the level of $25(\mathrm{OH}) \mathrm{D}$ in 161 children with BA and staged liver fibrosis in pathological specimens, and found that $25(\mathrm{OH}) \mathrm{D}$ level was negatively correlated with the stage of liver fibrosis. Peng et al. ${ }^{39}$ studied the correlation between 25(OH)D level and liver shear wave elastography in 33 children with BA after HPE, and found that 25(OH)VD level was negatively correlated with liver fibrosis severity.

Activation of HSCs and excessive deposition of extracellular matrix are two important pathological processes in liver fibrosis. Although the exact mechanism that regulates this process remains controversial, the TGF- $\beta$ signaling pathway is considered to be one of the major pathways that promote the accumulation of fibrotic extracellular matrix ${ }^{40}$. Previous animal studies have confirmed that the binding of active vitamin D and VDR can regulate activity of the TGF- $\beta$ signaling pathway in HSCs, thereby inhibiting expression of fibrosis genes and expression ${ }^{28,31}$ and deposition of types I and III collagen ${ }^{30,41}$. A recent study found that serum N-terminal peptide of procollagen III, an indicator of liver fibrosis, was negatively correlated with 25(OH)D in children with BA ${ }^{35}$. At present, there has been no study on the mechanism of $25(\mathrm{OH}) \mathrm{D}$ deficiency in $\mathrm{BA}$, nor on the mechanism of the relationship with liver fibrosis. Studies on the mechanism of the effect of vitamin D on liver fibrosis have mostly used cell lines and animal models of chemical damage, which is different from the pathological process of BA. In the present study, the primary HSCs of BA were used for the first time to verify the role of vitamin D activation disorder in the process of liver fibrosis. Since early and severe liver fibrosis is an important pathological feature of $\mathrm{BA}$, which is different from other cholestatic diseases, we adopted the animal model of biliary ligation to simulate the influence of vitamin $\mathrm{D}$ activation disorder on liver fibrosis in the case of cholestasis, which can reveal the role of vitamin $\mathrm{D}$ activation disorder in BA.

In our study, synthetic active vitamin D (calcitriol) was added to primary HSCs isolated from liver specimens from children with BA. The proliferation and migration of primary HSCs were decreased, along with expression of TGF- $\beta$, as well as Col-1 $\alpha 1, \alpha-$ SMA and TIMP-1. Expression of CYP2R1 in hepatic cells was upregulated or downregulated by gene transfection and coculture with HSCs. The results showed that upregulation of CYP2R1 also inhibited expression of hepatic-fibrosis-related genes such as TGF- $\beta 1$, Col-1 $1 \alpha 1$ and TIMP-1, and promoted expression of antifibrosis genes such as MMP-2. The expression of CYP2R1 in mice with biliary tract ligation was altered by gene transfection, and increased expression of CYP2R1 in vivo could significantly inhibit expression of hepatic-fibrosis-related genes. Therefore, it can be concluded from this study that deficiency of active vitamin $\mathrm{D}$ in $\mathrm{BA}$ can promote the formation of liver fibrosis, and the main reason for this deficiency is deficiency of CYP2R1, which leads to disorder of vitamin D activation. This finding provides a new therapeutic target and theoretical basis for the antifibrosis treatment of BA. However, the molecular biological mechanism of CYP2R1 deficiency in BA remains unclear, and its regulatory mechanism needs to be further studied.

Received: 27 April 2021; Accepted: 26 August 2021

Published online: 06 October 2021

\section{References}

1. Bezerra, J. A. et al. Biliary atresia: Clinical and research challenges for the Twenty-First Century. Hepatology 68(3), 1163-1173 (2018).

2. Fischler, B. \& Lamireau, T. Cholestasis in the newborn and infant. Clin. Res. Hepatol. Gastroenterol. 38(3), 263-267 (2014).

3. Shen, W. J. et al. Liver fibrosis in biliary atresia. World J. Pediatr. 15(2), 117-123 (2019).

4. Ortiz-Perez, A. et al. Innate immunity and pathogenesis of biliary atresia. Front Immunol. 11, 329 (2020).

5. Hasan, M. S. et al. Role of liver biopsy in the diagnosis of neonatal cholestasis due to biliary atresia. Mymensingh. Med. J. 27(4), 826-833 (2018).

6. Kheir, A. E. et al. Idiopathic neonatal hepatitis or extrahepatic biliary atresia? The role of liver biopsy. Sudan. J. Paediatr. 16(1), 58-62 (2016).

7. Lee, J. Y. et al. The value of preoperative liver biopsy in the diagnosis of extrahepatic biliary atresia: A systematic review and metaanalysis. J. Pediatr. Surg. 51(5), 753-761 (2016). 
8. Sakamoto, N. et al. The accumulation of regulatory T cells in the hepatic hilar lymph nodes in biliary atresia. Surg. Today 47(10), 1282-1286 (2017).

9. Pang, S. Y. et al. Autoimmune liver disease-related autoantibodies in patients with biliary atresia. World J. Gastroenterol. 24(3), 387-396 (2018).

10. Lages, C. S. et al. The dendritic cell-T helper 17-macrophage axis controls cholangiocyte injury and disease progression in murine and human biliary atresia. Hepatology 65(1), 174-188 (2017).

11. Brindley, S. M. et al. Cytomegalovirus-specific T-cell reactivity in biliary atresia at the time of diagnosis is associated with deficits in regulatory T cells. Hepatology 55(4), 1130-1138 (2012).

12. Zani, A. et al. Cytomegalovirus-associated biliary atresia: An aetiological and prognostic subgroup. J. Pediatr. Surg. 50(10), 1739$1745(2015)$.

13. Guijarro, T. et al. Detrimental pro-senescence effects of vitamin D on lung fibrosis. Mol. Med. 24(1), 64 (2018),

14. Arfian, N. et al. Vitamin D attenuates kidney fibrosis via reducing fibroblast expansion, inflammation, and epithelial cell apoptosis. Kobe. J. Med. Sci. 62(2), E38-E44 (2016).

15. Zhang, Z. et al. Preventive effects of vitamin D treatment on bleomycin-induced pulmonary fibrosis. Sci. Rep. 5, 17638 (2015).

16. Sun, Y. et al. Elevated serum 1,25(OH)2-vitamin D3 level attenuates renal tubulointerstitial fibrosis induced by unilateral ureteral obstruction in kl/kl mice. Sci. Rep. 4, 6563 (2014).

17. Rai, V. \& Agrawal, D. K. Role of vitamin D in cardiovascular diseases. Endocrinol. Metab. Clin. North Am. 46(4), 1039-1059 (2017).

18. Tzilas, V. et al. Vitamin D prevents experimental lung fibrosis and predicts survival in patients with idiopathic pulmonary fibrosis. Pulm. Pharmacol. Ther. 55, 17-24 (2019).

19. Gascon-Barre, M. et al. The normal liver harbors the vitamin D nuclear receptor in nonparenchymal and biliary epithelial cells. Hepatology 37(5), 1034-1042 (2003).

20. Petta, S. et al. Low vitamin D serum level is related to severe fibrosis and low responsiveness to interferon-based therapy in genotype 1 chronic hepatitis C. Hepatology 51(4), 1158-1167 (2010).

21. Yang, B. B. et al. Low vitamin D status is associated with advanced liver fibrosis in patients with nonalcoholic fatty liver disease. Endocrine 55(2), 582-590 (2017).

22. Buonomo, A. R. et al. Severe vitamin D deficiency increases mortality among patients with liver cirrhosis regardless of the presence of HCC. In Vivo 33(1), 177-182 (2019).

23. Konstantakis, C., Tselekouni, P. \& Kalafateli, M., et al. Vitamin D deficiency in patients with liver cirrhosis (2016).

24. Chen, T. et al. The effect of vitamin D supplementation on the progression of fibrosis in patients with chronic liver disease: A protocol for a systematic review and meta-analysis. Medicine (Baltimore) 99(19), e20296 (2020).

25. Ebrahimpour-Koujan, S. et al. Effects of vitamin D supplementation on liver fibrogenic factors in non-alcoholic fatty liver patients with steatohepatitis: Study protocol for a randomized clinical trial. Trials 20(1), 153 (2019).

26. Tanaka, A. et al. Vitamin D receptor polymorphisms are associated with increased susceptibility to primary biliary cirrhosis in Japanese and Italian populations. J. Hepatol. 50(6), 1202-1209 (2009).

27. Arai, T. et al. Association of vitamin D levels and vitamin D-related gene polymorphisms with liver fibrosis in patients with biopsyproven nonalcoholic fatty liver disease. Dig. Liver Dis. 51(7), 1036-1042 (2019).

28. Abramovitch, S. et al. Vitamin D inhibits proliferation and profibrotic marker expression in hepatic stellate cells and decreases thioacetamide-induced liver fibrosis in rats. Gut 60(12), 1728-1737 (2011).

29. Reiter, F. P. et al. Antifibrotic effects of hypocalcemic vitamin D analogs in murine and human hepatic stellate cells and in the $\mathrm{CCl} 4$ mouse model. Lab. Invest. 99(12), 1906-1917 (2019).

30. Artaza, J. N. \& Norris, K. C. Vitamin D reduces the expression of collagen and key profibrotic factors by inducing an antifibrotic phenotype in mesenchymal multipotent cells. J. Endocrinol. 200(2), 207-221 (2009).

31. Ding, N. et al. A vitamin D receptor/SMAD genomic circuit gates hepatic fibrotic response. Cell 153(3), 601-613 (2013).

32. Keane, J. T. et al. Vitamin D and the liver-correlation or cause?. Nutrients 10(4), 496 (2018).

33. Kobayashi, A. et al. Serum 25-hydroxy-vitamin D in hepatobiliary disease in infancy. Arch. Dis. Child 54(5), 367-370 (1979).

34. Ng, J. et al. Vitamin D levels in infants with biliary atresia: Pre- and post-kasai portoenterostomy. J. Pediatr. Gastroenterol. Nutr. 62(5), 746-750 (2016).

35. Zhuang, P. et al. Associations between vitamin D and liver function and liver fibrosis in patients with biliary atresia. Gastroenterol. Res. Pract. 2019, 4621372 (2019).

36. Cheng, J. B. et al. De-orphanization of cytochrome P450 2R1: A microsomal vitamin D 25-hydroxilase. J. Biol. Chem. 278(39), 38084-38093 (2003).

37. Cheng, J. B. et al. Genetic evidence that the human CYP2R1 enzyme is a key vitamin D 25-hydroxylase. Proc. Natl. Acad. Sci. U S A 101(20), 7711-7715 (2004).

38. Shinkyo, R. et al. Metabolism of vitamin D by human microsomal CYP2R1. Biochem. Biophys. Res. Commun. 324(1), 451-457 (2004).

39. Peng, C. et al. Serum vitamin D level is inversely associated with liver fibrosis in post Kasai's portoenterostomy biliary atresia patients living with native liver. PLoS ONE 14(6), e218896 (2019).

40. Inagaki, Y. \& Okazaki, I. Emerging insights into Transforming growth factor beta Smad signal in hepatic fibrogenesis. Gut 56(2), 284-292 (2007).

41. Udomsinprasert, W. \& Jittikoon, J. Vitamin D and liver fibrosis: Molecular mechanisms and clinical studies. Biomed. Pharmacother. 109, 1351-1360 (2019).

\section{Author contributions}

Study conception and design: S.S., G.C., R.D., S.Z. Implementation of the experiment: S.S., M.X., P.Z. Data acquisition: S.S., M.X., P.Z., R.D. Analysis and data interpretation: S.S., M.X., P.Z., S.Z. Drafting of the manuscript: S.S., P.Z., M.X. Critical revision: G.C., K.D., R.D., S.Z. All authors reviewed the manuscript.

\section{Funding}

The authors have no financial relationships relevant to this article to disclose. This study received financial support from the National Natural Science Foundation of China (Nos. 81700450), Clinical Research Plan of SHDC (No. SHDC2020CR2009A) and Shanghai Municipal Key Clinical Specialty (No. shslczdzk05703). This study was approved by the Ethics Committee of the Children's Hospital of Fudan University.

\section{Competing interests}

The authors declare no competing interests. 


\section{Additional information}

Supplementary Information The online version contains supplementary material available at https://doi.org/ 10.1038/s41598-021-99158-3.

Correspondence and requests for materials should be addressed to R.D. or S.Z.

Reprints and permissions information is available at www.nature.com/reprints.

Publisher's note Springer Nature remains neutral with regard to jurisdictional claims in published maps and institutional affiliations.

(c) (i) Open Access This article is licensed under a Creative Commons Attribution 4.0 International License, which permits use, sharing, adaptation, distribution and reproduction in any medium or format, as long as you give appropriate credit to the original author(s) and the source, provide a link to the Creative Commons licence, and indicate if changes were made. The images or other third party material in this article are included in the article's Creative Commons licence, unless indicated otherwise in a credit line to the material. If material is not included in the article's Creative Commons licence and your intended use is not permitted by statutory regulation or exceeds the permitted use, you will need to obtain permission directly from the copyright holder. To view a copy of this licence, visit http://creativecommons.org/licenses/by/4.0/.

(C) The Author(s) 2021 